\title{
An Emergency Evacuation Planning Model for Special Needs Populations Using Public Transit Systems
}

\author{
Evangelos I. Kaisar, Ph.D., Florida Atlantic University \\ Linda Hess, E.I., Stanley Consultants, Inc. \\ Alicia Benazir Portal Palomo, E.I., Florida Atlantic University
}

\begin{abstract}
The need to have evacuation plans in place for ready implementation for special needs populations became evident after catastrophic events such as Hurricane Katrina. For the purpose of this study, special needs populations will include, but are not limited to, people with physical disabilities, older adults, non-English-speaking populations, residents and employees without vehicles, and tourists. The main objective of this study was to evaluate different evacuation procedures for special needs populations from large urban areas using current public transit systems. A microscopic simulation model was constructed to analyze real-life scenarios for evacuation methodologies. A linear programming optimization model was developed to find the optimum locations for evacuation bus stops for the case study area. The results from this study are very interesting and can aid evacuation planners in the future.
\end{abstract}

\section{Introduction}

In the past decade, large catastrophic events such as terrorist attacks and natural disasters have disrupted regional urban areas and raised awareness of mass evacu- 
ation. Advancements in technology are allowing planners to develop more efficient and effective emergency preparedness strategies to protect the general public from danger (Laben 2002). It has become evident that our society faces many dangers, and being prepared for them is one means of defense.

Catastrophic events are inevitable and pose great threat to our society. Depending on the size and demographics of the evacuation area and the type of event, evacuation procedures can vary. Through the use of reproducing traffic network behavior, simulation models provide realistic results that aid in effective evacuation planning (Di Gangi et al. 2009; Mastrogiannidou et al. 2009). The threat of man-made or natural disasters disturbing everyday life has created a need for emergency evacuation methodologies to be common knowledge to the public for quick implementation of such procedures (Mannan and Kilpatrick 2000). To be capable of quick response, city officials should have a plan of action already in place to vacate highly-populated urban areas at risk.

The type of evacuation methodology executed is also dependent on the location and size of the area being vacated. The population and infrastructure of a city can differ based on the time period and location of its establishment. Urban areas tend to have many residents living very close together with varying demographics. To efficiently evacuate all citizens of an area, particular needs of certain groups of citizens need to be taken into consideration. The issue of evacuating special needs population has become more prevalent with current events such as Hurricane Katrina (Litman 2006). The difficulty in evacuating populations with special needs varies based on the extra assistance needed by those individuals.

The aftermath of the terrorist attacks on New York City and the Pentagon on September 11, 2001, demonstrated the importance of evacuation and disaster planning for highly-populated urban areas. Large numbers of citizens are concentrated in these areas, especially during workdays, creating a vulnerable target for terrorists. These areas with high concentrations of population can lead to high casuality rates if they are not evacuated quickly. Road networks become fully saturated in evacuation scenarios due to a large number of vacating vehicles; using public transit is one alternative to improve the level of service during evacuation procedures.

Without proper planning, public transit systems can falter in the aid of emergency evacuation (Renne et al. 2008). Bus drivers need to be aware if they are required to provide services during evacuations and, if so, the location of evacuation bus stops and routes. 
This study focuses on developing a public transit routing scenario to best serve special needs populations in the downtown core area of the District of Columbia (Washington, D.C.). The main goal of this study was to evaluate different evacuation procedures for special needs populations from large urban areas during a no-warning emergency using current public transit systems. For the purpose of the study, special needs populations include, but are not limited to, people with physical disabilities, older adults, non-English-speaking populations, residents and employees without vehicles, and tourists. The specific objectives to reach this goal are as follows:

- Propose optimum locations for evacuation bus stops.

- Construct a realistic microscopic simulation model of a transportation network.

- Reduce evacuation time for public transit vehicles through optimum bus stop locations.

A major part of Washington, D.C. metropolitan area being evaluated for this study includes one of the busiest Metrorail stations in the metropolitan area, Gallery Place/Chinatown station. The current infrastructure and public transportation systems presently in place in Washington, D.C were used to hypothetically evacuate the entire population of the core downtown area. All the evacuation scenarios included ensuring that populations with special needs were evacuated as well. Through the use of computer modeling, different emergency evacuation methodologies and scenarios were assessed. Emergency evacuations are becoming more commonplace, and metropolitan planning organizations (MPOs) and transportation engineers are assessing these new planning requirements, especially in the case of the nation's capital.

\section{Literature Review}

Transportation networks can be evaluated on three different levels, depending on the purpose of the analysis: microscopic, mesoscopic, and macroscopic. As traffic computer simulations evolve, hybrid models are meshing components from several different models to better represent real traffic networks (Lerner et al. 2001; Burghout et al. 2005). Microscopic scales prove to be more effective for smaller road networks, given the large number of inputs needed to build and calibrate the models (Mastrogiannidou 2009; Chiu and Mirchandani 2008; Lerner et al. 2001). A study that used a hybrid simulation platform of micro and mesoscopic analysis was performed by Coolahan et al. (2009). In their study, the Traffic Simulation System 
AIMSUN NG 6.0 was used to perform microscopic and mesoscopic simulations on the Baltimore, Maryland, road network in the case of a smallpox release.

Chen and Zhan (2008) conducted an agent-based modeling study on three different types of road networks - a grid network, a ring road structure, and a real road network (see Figure 1) - proving that, "there is no evacuation strategy that can be considered as the best strategy across different road network structures and the performance of the strategies depends on both road network structure and population density" (Chen and Zhan 2008, 26).

For the purpose of this study, only one type of network, the road structure of Washington, D.C., was used to find the shortest evacuation clearance time when implementing different public transit strategies. Degnan et al. (2009) used one road simulation network to evaluate and compare several different types of evacuation methodologies. The four main strategies included nearest exit, reference, management, and staged. The "nearest exit" strategy used the shortest distance traveled from the event location to the exit location in order to evacuate the network. The "reference" strategy evacuated cars based on the exits that were assigned in advance according to network characteristics. The "management" strategy applied various management policies based on local agency requirements and procedures, such as those of the police department, city planning office, etc. The "staged" strategy evacuated the network in stages based on the previously-determined Traffic Analysis Zones (TAZs) and network capacity. The analysis was based on three different measure of effectiveness: evacuation time, total travel time, and lost vehicles. The evacuation methodology "reference" scored the lowest, with the other three methodologies yielding close results.

Liu et al. (2008) performed a corridor-based evacuation of Washington, D.C. assuming a terrorist attack on Union Station and evacuating only the six surrounding TAZs (see Figure 2). Using a GIS-based input module, they were able to determine the amount of flow on surrounding evacuation corridors. Studies focusing on communal transport, such as buses, to aid in mass evacuation for highly-populated areas are starting to become more common after the effects of Hurricane Katrina and Rita (He et al. 2009). When using buses for evacuation purposes, the main goal is to minimize the delay and the distance a bus has to travel in order to maximize the number of trips the bus can make in and out of the network (Johnston and Nee 2006). He et al. (2009) proposed a hybrid Artificial Neural Network (ANN), a mathematical model that is inspired by the structure of biological neural networks, composed of a general algorithm and climbing method to solve a location-routing 


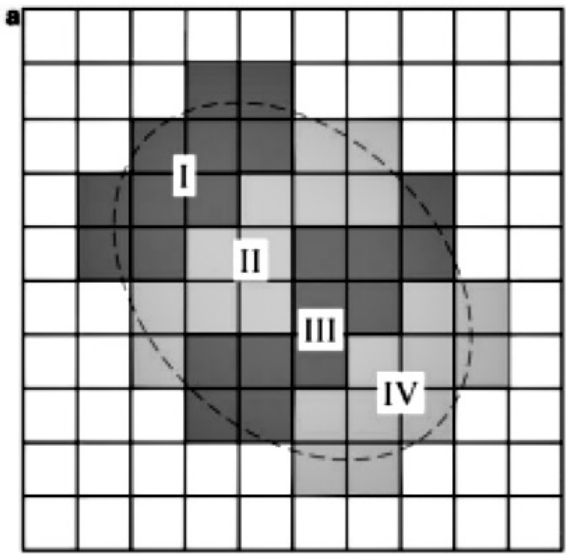

b

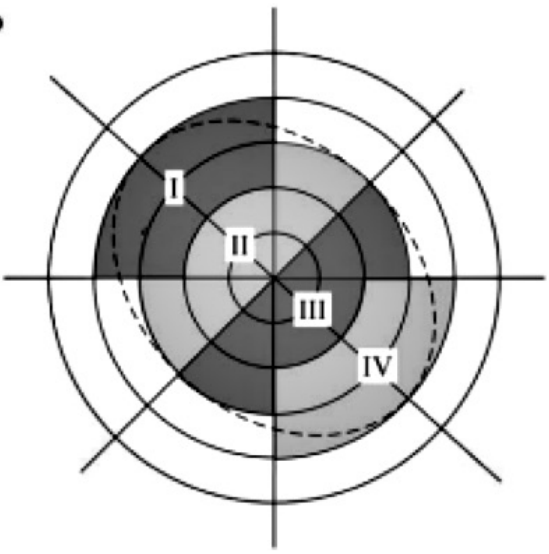

c

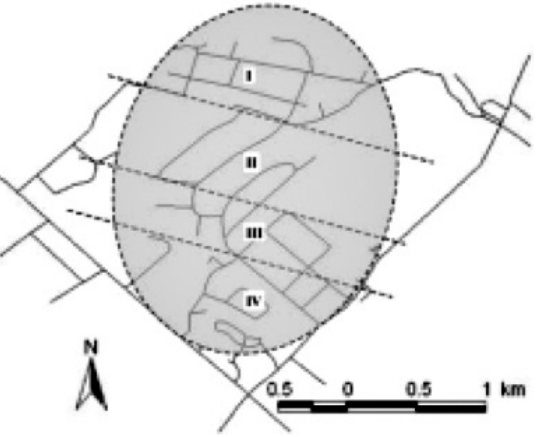

Source: Chen and Zhan (2008)

Figure 1. Simulated road networks: (a) grid road network, (b) ring road network, (c) real road network 
problem for transit-dependent residents. They ran two scenarios-a one-stage and a two-stage transit evacuation using buses in Gulfport, Mississippi. This study did not incorporate a staged evacuation procedure but did not rule out buses making round trips to pick up more evacuees.

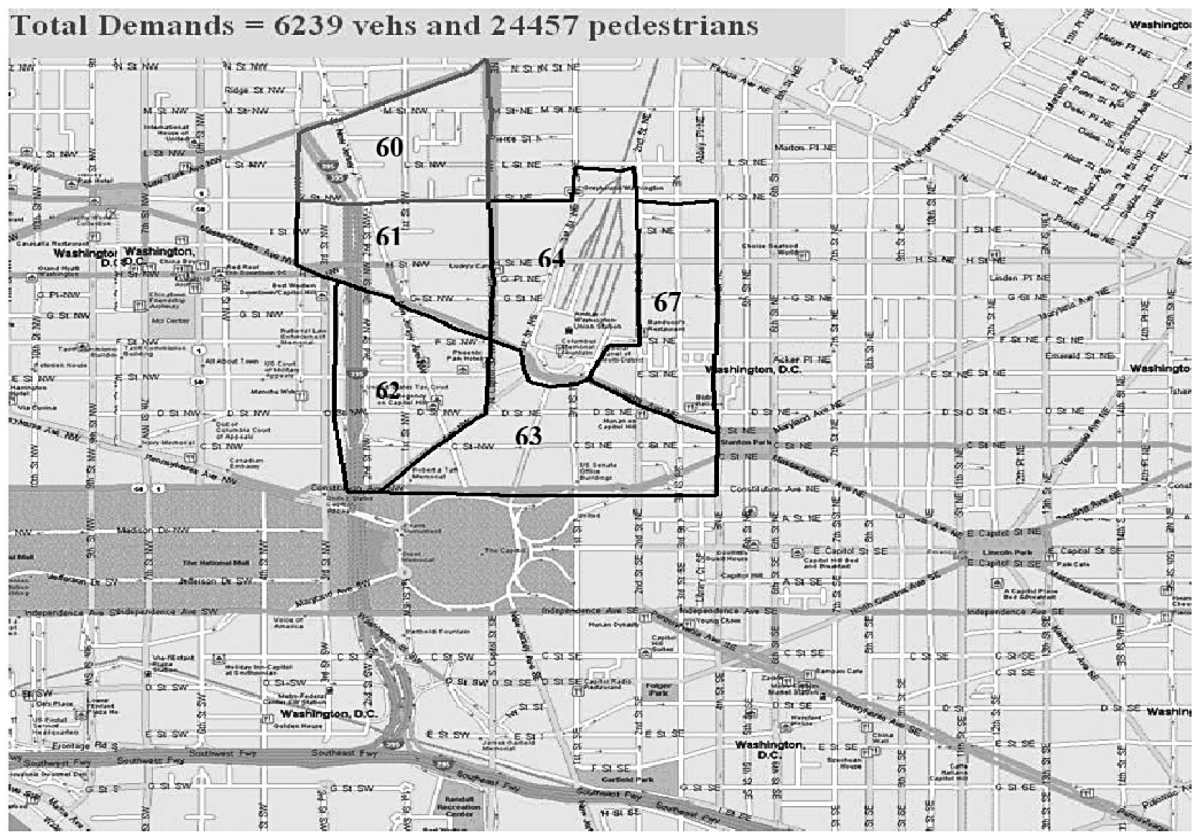

Source: Liu et al. (2008)

\section{Figure 2. Impact area of emergency incident}

Terrorists are aware of the vulnerability of public transit systems and have begun to target them directly. With time and advancing technology, terrorist attacks on public transit systems are becoming more severe and a larger threat. Bus, rail, and metro stations are attractive targets for terrorists because of the large congregation of passengers, such as a crowded bus with standees or a downtown subway platform at rush hour (Rabkin et al. 2004). Other than just the crowds that generate a terrorist's focus, the public transport system can supply the means or ends of a terrorist attack. 


\section{Methodology}

Considering the large size and specific demographics of special needs populations located within the boundaries of the microscopic simulation network, origin-destination matrices (O-D) were used to produce the traffic demands. The safe zones were used to represent a safe location that is a safe distance from the hazardous area and are strategically placed according to current evacuation plans in place by city officials.

To combine TAZs not occupying the virtual network, the Thiessen polygon method was used. Thiessen polygons are "mathematically defined by the perpendicular bisectors of the lines between all points" (ET Geo Wizards). For a given number of spatially-distributed points, the Thiessen polygon method is capable of producing their respective areas of influence; for this application, the contribution area is for a safe zone centroid. Using the Thiessen polygon generation feature of ArcGIS 9.3 and the nine safe zone centroids, the polygons were created and incorporated all the TAZ trip information provided by the MPO (see Figure 3).

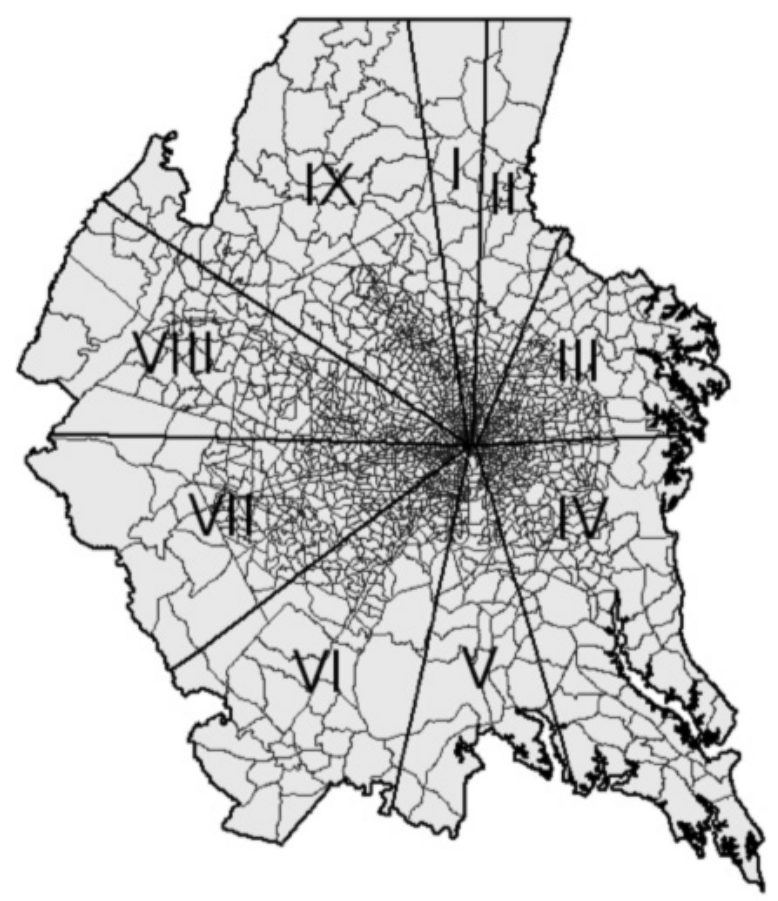

Figure 3. Thiessen polygon distribution of outer TAZs 


$$
\begin{aligned}
& T_{i, j}=\left(\frac{A_{i, j}}{A_{i}} * T\right) \\
& T_{j}=\sum_{i=1}^{I} T_{i, j} \mathrm{j}=1,2,3 \ldots 9 \\
& T i, j= \begin{cases}0 & \text { if } \mathrm{i} \not \subset \mathrm{j} \\
T i, j & \text { otherwise }\end{cases}
\end{aligned}
$$

Where,

$T_{i, j}=$ Trips originating in traffic analysis zone $i$ associated with safe zone $j$

$A_{i, j}=$ Area of traffic analysis zone $i$ within safe zone $j$

$A_{i}=$ Area of traffic analysis zone $i$

$T_{j}=$ Total number of trips associated with safe zone $j$

The goal of this evacuation methodology was to relocate all people located inside the network to safe zones. The safe zones are located outside the network along major roadways that currently act as evacuation routes for the city. The simulation model used for this analysis had a total of nine safe zones (Figure 3). The safe zones are the only zones in the model that produced travel demand. This is due to the assumptioin of a no-warning evacuation, not allowing people to return home before evacuating. It is assumed that once vehicles in the network reach these safe points, they are no longer in harm's way and can continue safely to shelters. The traffic demand of each safe zone was obtained based on its attractiveness as a function of the inverse distance between it and the traffic production areas.

The first step in developing the evacuation O-D matrices required obtaining the trip production for each TAZ. Using demographics obtained from the U.S. Census Bureau, trip production for personal vehicles in each TAZ was calculated using empirical equations. The number of people in each TAZ that rely on public transit for evacuation was obtained from further analysis of demographic data. To estimate the number of people without a vehicle, the total number of people using personal vehicles was subtracted from the total number of people located in that zone during the evacuation scenario. Using U.S. Census data, the number of people with physical disabilities, older adults, foreign populations, and low-income households in each TAZ was used to give that TAZ a higher priority for bus routing during evacuation.

After the number of vehicles for each TAZ was known, personal vehicle trips were assigned to safe zones. Human driver behavior is extremely difficult to predict, 
especially in mass emergency evacuations (Alsnih and Stopher 2004; Degnan et al. 2009). In this analysis, the main focus was on the exit of public transit vehicles such as buses that have a fixed set route for evacuation. To have the road network properly loaded with personal vehicles in order to simulate how well bus routes serve special needs populations in an evacuation, a trip assignment procedure was developed. The assignment of personal vehicles to a particular safe zone was completed following an inverse distance relationship between the origin and the destination, as defined by Equations 4-11.

$$
\begin{aligned}
& V_{z, j}^{\prime}=f\left(d_{z, j}, V_{2}, n_{j}\right) \\
& d_{z, j}=\sqrt{\left(x_{z}-x_{j}\right)^{2}+\left(y_{z}-y_{j}\right)^{2}} \\
& V_{z, j}^{\prime}=\left\{\begin{array}{lr}
0 & \text { If } \mathrm{d}_{z, j} \geq d_{\max } \\
f\left(d_{z, j}, V_{z}, n_{j}\right) & \text { otherwise }
\end{array}\right. \\
& w_{z, j}=1-\left[\left(\frac{d_{z, j}}{\sum_{j=1}^{J} d_{z, j}}\right) * \lambda_{z}\right] \\
& w_{z, j}= \begin{cases}0 & \text { if } w_{z, j} \leq 0 \\
w_{z, j} & \text { otherwise }\end{cases} \\
& \lambda_{z}= \begin{cases}3 & \text { if } \mathrm{n}_{\mathrm{j}} \geq 4 \\
2 & \text { if } \mathrm{n}_{\mathrm{j}}=3 \\
1 & \text { otherwise }\end{cases} \\
& R_{z, j}=\frac{w_{z, j}}{\sum_{j=1}^{j} w_{z, j}} \\
& V_{z, j}^{\prime}=R_{z, j} V_{z}
\end{aligned}
$$

Where:

$$
\begin{aligned}
& n_{j}=\text { number of safe zones }(j) \text { within } d_{\max } \text { of zone }(z) \\
& v_{z, j}=\text { number of cars in TAZ }(z) \text { to safe zone }(j) \\
& D_{z, j}=\text { distance between TAZ }(z) \text { and safe zone }(j) \\
& w_{z, j}=\text { "attractiveness" for cars from TAZ }(z) \text { to safe zone }(j)
\end{aligned}
$$


$\lambda_{z}=$ adjustment factor for each TAZ ( $z$ ) as a function of the number of safe zones $(\mathrm{j})$ within $\mathrm{d}_{\max }$

$\mathrm{d}_{\max }=$ maximum distance for a safe zone to be a feasible safe zone

$x, y=$ coordinates of $z$ and $j$

$\mathrm{R}_{\mathrm{z}, \mathrm{j}}=$ "attractiveness" ratio

The distance of each TAZ to all safe zones was found using the centroid of the zone. The centroids of each traffic zone were found by implementing Hawth's Analysis Tools for ArcGIS 9. The latitude and longitude for each TAZ and safe zone centroid were then documented and used to find the Euclidean distance.

\section{Mathematical Model of Bus Stop Locations}

The goal of this mathematical model is to maximize the overall benefit of evacuation bus stops located within the case study area using linear programming with binary variables. The objective function and constraints are presented as follows:

$\operatorname{Maximize} \sum_{b=1}^{B} \beta_{b, z} \phi_{b, z} \quad \forall z$

Subject to:

$$
\begin{aligned}
& \beta_{b}=w_{m} \sum_{m=1}^{M}\left(\frac{1}{d_{b, m} \psi_{b, m}}\right)+w_{v} \sum_{v=1}^{V}\left(p_{v} * \frac{1}{d_{b, v} \psi_{b, v}}\right)+w_{l} \sum_{i=1}^{L}\left(p_{l} * \frac{1}{d_{b, l} \psi_{b, l}}\right) \\
& +w_{e} \sum_{e=1}^{E}\left(p_{e} * \frac{1}{d_{b, e} \psi_{b, e}}\right)+w_{o} \sum_{o=1}^{O}\left(p_{o} * \frac{1}{d_{b, o} \psi_{b, o}}\right)+w_{s} \sum_{s=1}^{S}\left(p_{s} * \frac{1}{d_{b, s} \psi_{b, s}}\right) \forall b, z \\
& N_{z}^{\max }=f\left(T_{z}, A_{z}\right) \quad \forall z \\
& N_{z}^{\max }=\sum_{b=1}^{B} \phi_{b, z} \quad \forall z \\
& \sum_{z=1}^{Z} \phi_{b, z} \leq \eta \quad \forall b \\
& \phi_{b, z}=\{0,1\}
\end{aligned}
$$




$$
\begin{aligned}
& N_{z}^{\max }= \begin{cases}\frac{A_{z}}{A_{b}^{\max }} & \text { if } \frac{A_{z}}{A_{b}^{\max }} \geq \frac{T_{z}}{T_{b}^{\max }} \quad \forall b, z \\
\frac{T_{z}}{T_{b}^{\max }} & \text { otherwise }\end{cases} \\
& N_{z}^{\max }= \begin{cases}0 & \text { if } \\
N_{z}^{\max } & N_{z}^{\operatorname{maz}} \leq \xi\end{cases}
\end{aligned}
$$

Where,

$\phi=$ binary decision variable

$\beta=$ benefit of bus stop

$\mathrm{b}=$ bus stop

$\mathrm{z}=$ traffic analysis zone

$\mathrm{N}=$ number of bus stops

$\mathrm{m}=$ Metrorail station

$\mathrm{d}=$ distance

$\psi=$ distance factor

$v=$ persons that do not own a vehicle

$\mathrm{e}=$ persons over the age of 65

I = person with a low income below poverty line

$\mathrm{s}=$ persons with physical disabilities

$y=$ employees

$\mathrm{w}=$ weight defined by the decision maker to a criteria category

$\mathrm{p}=$ size of special needs population

$\mathrm{T}=$ bus trips required to evacuate special needs population

$A=$ area

$\zeta=$ minimum $\mathrm{N}^{\max }$ value necessary to have a bus stop

$\eta=$ maximum total number of bus stops for the entire study area 
The objective function is to maximize the overall benefit of chosen evacuation bus stops. Binary variables $\left(\phi_{b, z}\right)$ are decision variables within the optimization model used to define which bus stops are chosen, constrained by a maximum number of bus stops per TAZ $\left(N_{z}^{\text {max }}\right)$ and also for the area of study $(\eta)$. The optimization assigns a maximum number of bus stops to each TAZ within the case study area (Eqs. 14, 15, 18, 19). The total number of bus stop locations that can be selected for the area is set be Eq. 16. The criterion for selecting evacuation bus stops is associated with the weighted bus stop benefit $\left(\beta_{b, z}\right)$. For bus stops that are selected, the binary variable assumes a value of 1 , so that the benefit is added to the objective function.

The benefit associated with each bus stop is based on a function that aggregates distance and population attributes associated with each bus stop (Eq. 13). The specific benefit of bus stations is based solely on its inverse distance to a given bus stop. However, for other groups of interest, such as special needs populations, the size of population $(p)$ of each special needs group will introduce another factor to the benefit function. For instance, a bus stop located near a larger population of people with physical disabilities will have a higher benefit than a lower population for the same given distance.

In an evacuation scenario, using all available bus stops is not a feasible solution based on time constraints. Therefore, a maximum number of bus stops $(\eta)$ needs to be specified to reduce delay times related to frequent stops (Eq. 16). Moreover, the objective function that attempts to maximize the overall benefit of bus stops can lead to the optimum location of bus stops to be clustered in one area, representing the greater benefit value in the whole study area. Eq.15 was introduced to inhibit a grouping of bus stops in each TAZ. By dividing the study area into several different TAZs, a maximum number of bus stops can be defined per zone, limiting the number of bus stops in one TAZ area. The maximum number of bus stops that can be chosen for a zone $\left(N_{z}^{\text {max }}\right)$ is a function of bus trips required and area of the zone, as defined by Eq. 14. This model allows for the decision maker to determine how many trips one bus stop can serve. That maximum number of trips ( $\left.T^{\max }\right)$ is then divided by the entire number of trips required for the zone, producing the number of needed bus stops. The decision maker must also decide what the maximum square area will be for requiring a bus stop. The entire square area of the zone is then divided by this set area, and another number of needed bus stops is produced. The formulation then uses the larger of the two values to set equal to $N_{z}^{\text {max }}$. If the total number of trips needed and the area of a zone do not reach a set value $(\zeta)$, 
it is reasonable to assume that $N_{z}^{\max }$ can equal 0 , stating that no bus stops will be assigned to that particular zone.

Other constraints can be defined to specify the desired number of bus stops for a specific TAZ, overriding the function previously described. If one particular TAZ was not assigned an evacuation bus stop and the need for a bus stop at that particular location is understood by the decision maker, an equality or inequality constraint can be declared. For example, for $z=23$, no bus stop was originally assigned, but by declaring Eq. 20 as a constraint, three bus stops are enforced:

$$
N_{23}^{\max }=3
$$

Once the total benefit for evacuation bus stops is reached, it is important to note the location within the entire case study. The purpose of this model is to maximize the evacuation of a specific demographic. The combination of a limited number of available bus stops ( $N^{\max }$ ) and bus stops with low benefit value may cause certain areas not to have any assigned bus stops. The constraint presented in Eq. 20 may overcome this issue; however, if a larger area encompassing several TAZs does not contain any selected evacuation bus stops, the decision maker may declare another constraint so that the optimization will assign to the referred area a given number of bus stops based on selecting those with a greater benefit. For example, if four TAZs $(z=10,11,12,13)$ have very small special needs populations and no bus stop is identified within this area, as the associated benefit is low compared to other areas, the decision maker can declare the constraint to still include them within the model:

$$
N_{10}^{\max }+N_{11}^{\max }+N_{12}^{\max }+N_{13}^{\max } \geq 1
$$

If the decision maker finds that the optimum bus stop locations are clustering in one region of the evacuation area, and applying constraints such as Eq. 21 would become too repetitive, the area can be spatially divided. By dividing the area into smaller sub-sections, zones can be grouped together, and a minimum number of bus stops can be set for the sub-section. This would allow a more even spatial assignment of evacuation bus stops. Despite the complexity of the given formulation, the model proves to be flexible, satisfying the decision maker's needs in evacuation planning for all study areas.

The computational time requirements to achieve the optimal solution were minimal, approximately three seconds. For comparison purposes, the same formulation was optimized using a Genetic Algorithms solver, requiring considerable computa- 
tional time for the convergence to the same optimal solution. It was then decided that a linear programming approach was the best for this research.

\section{Case Study}

For this study, the downtown core area of Washington, D.C. was selected to be analyzed. The challenges faced in evacuating this specific area incorporate the large diverse urban population, prestigious government buildings, a complicated road network, and a significant quantity of population that depends on public transportation. Reported by the U.S. Census Bureau, the District of Columbia had a population of 591,833 in 2008 . On weekdays, this figure can increase by 72 percent, with an additional 410,000 people entering the city for business purposes (Longley 2005).

The nation's capital has one of the most efficient public transit systems in the country, operating under the Washington Metropolitan Area Transit Authority (WMATA). The Washington Metropolitan Area Transit Compact joined public and private transit companies in its jurisdiction in order to have an efficient regional transit service.

Current evacuation plans for Washington, D.C. are composed of 19 major corridors. Secondary route choices have also been designated by the District Department of Transportation (DDOT), allowing for flexibility to transfer from one primary exit route to another if needed. These routes are defined in the evacuation map of Washington, D.C. in Figure 4.

A microscopic simulation model of the Washington, D.C. core downtown area was constructed in the simulation platform AIMSUN NG 6.0. AIMSUN uses objectoriented simulators and a graphical user interface to produce 2D/3D animations of the road traffic network. Real traffic conditions for different road networks can be modeled in AIMSUN using built-in functions such as lane changing, car following, and gap acceptance (Xiao et al. 2005; Barcelo et al. 2004).

All signalized intersections were calibrated using the signal optimization software Synchro. Three sets of signal timing files were collected in total: AM peak hours (7am to 9am), Midday-off peak hours (10am to 2pm), and PM peak hours (3pm to $7 \mathrm{pm}$ ). To calibrate and validate the road geometry and signal timings of the computer model, everyday background traffic was used. Everyday traffic demand was provided in O-D matrices and was validated using 2006 traffic counts from DDOT. These everyday O-D matrices were received from the agency through the Metropolitan Washington Council of Governments (MWCOG), the National Capital Region Transportation Planning Board (TPB). The everyday matrices were used 


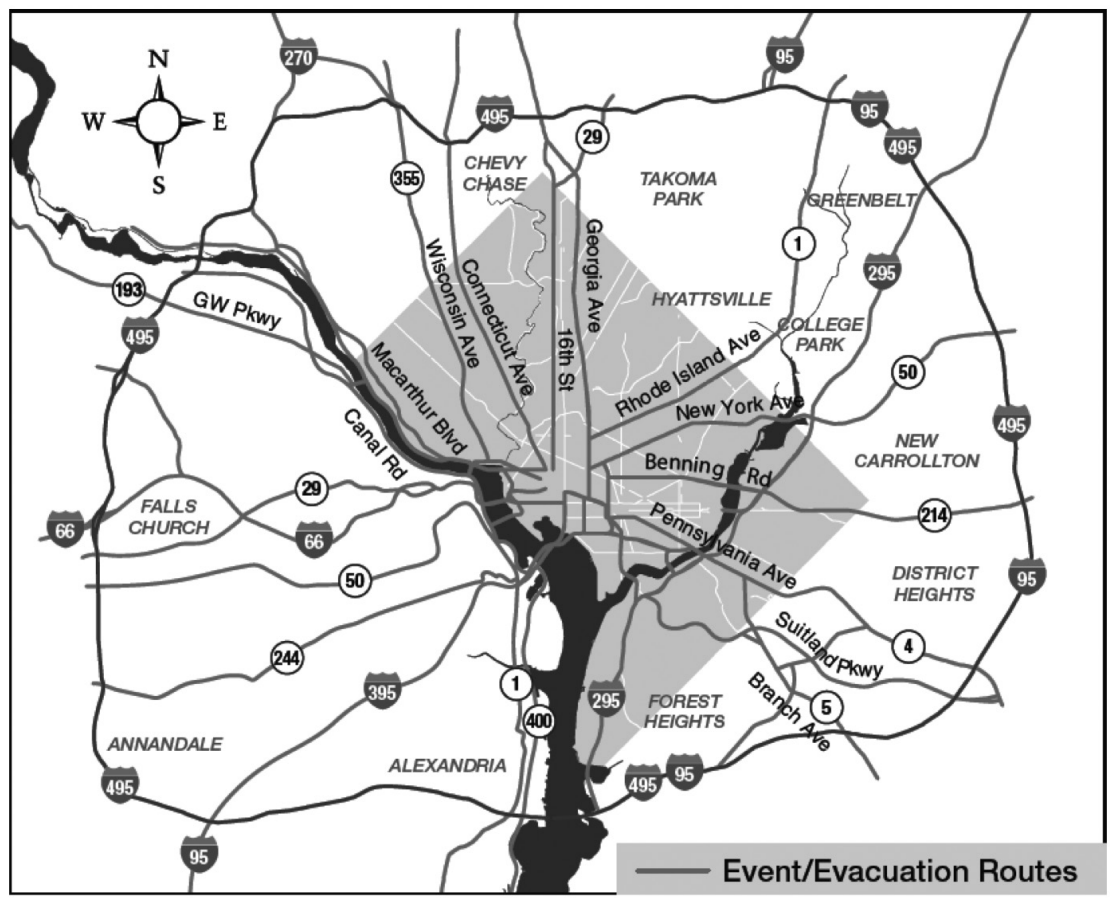

Source: DDOT, 2002

Figure 4. Evacuation routes for District of Columbia

to produce background traffic on the model before the evacuation commenced and validated the model when compared to traffic counts. The O-D matrices were given in the computer software package Cube Voyager.

\section{Results}

The results of the research fall into two main categories: the mathematical model and the simulation model. The simulation model was dependent on the results found from the optimization model. After reviewing the results from the optimization model, it was decided to execute the model for a second time with added spatial constraints before simulating the results.

\section{Mathematical Model Results}

The mathematical results yielded the total benefit of evacuation bus stops according to the weighting scheme and maximum number of bus stop occurrences, both of which are dependent upon the decision maker's preferences. 
It was noted that the there is some relationship between the individuals found in the categories chosen for the mathematical model. Persons who choose not to own a vehicle could be influenced by a low income. Older adults and persons with physical disabilities might find it difficult to work and result in falling into the category of low income as well. Considering this relationship, an individual might be accounted for twice. Therefore, a weighting scheme was developed to carefully account for all special needs populations without overemphasizing one group or another.

Finding a correlation between the categories was not possible due to the fact that some of the data for certain categories was based on percentages of total population, resulting in an inaccurate correlation very close to 1 . A sensitivity analysis was performed to find the most representative weighting scheme for the given case study area. The optimization model was executed 10 times for each maximum number of bus stop occurrences $(\eta)$. For each weighting scheme, the frequency that the $\eta$ best ranked bus stops occurs for all weighing schemes and for all $\eta$ maximum number of bus stops scenarios was graphed. The scenario that most frequently selected the same bus stop locations for all 10 scenarios was then chosen for simulation purposes. The weights adopted for weighting scheme 6 produced the best weights for bus stop locations in the application of this case study because of the weights being distributed evenly among all the special needs population categories.

The bus stop locations yielded from the optimization model proved to have the highest benefit for special needs populations in the downtown Washington, D.C. core area. As expected, the total benefit increased as the total number of maximum optimum bus stops increased. Each condition always included the optimum bus stops selected in the preceding condition.

The total benefit found for the 20 bus stop locations was 42.88 and was one of the highest among all 10 of the weighting scenarios for the 20-maximum-busstops scenario. Even though this scenario produced one of the highest benefits, the location of bus stops is not ideal for planning purposes, because the majority of selected stops were located and clustered in the area northwest of the White House (Figure 5a). Therefore, the majority of the downtown area does not contain any evacuation bus stops. The low number of evacuation bus stops with the addition of clustering results in only a few TAZs containing evacuation stops, leaving most of the zones empty without any evacuation bus stops. 


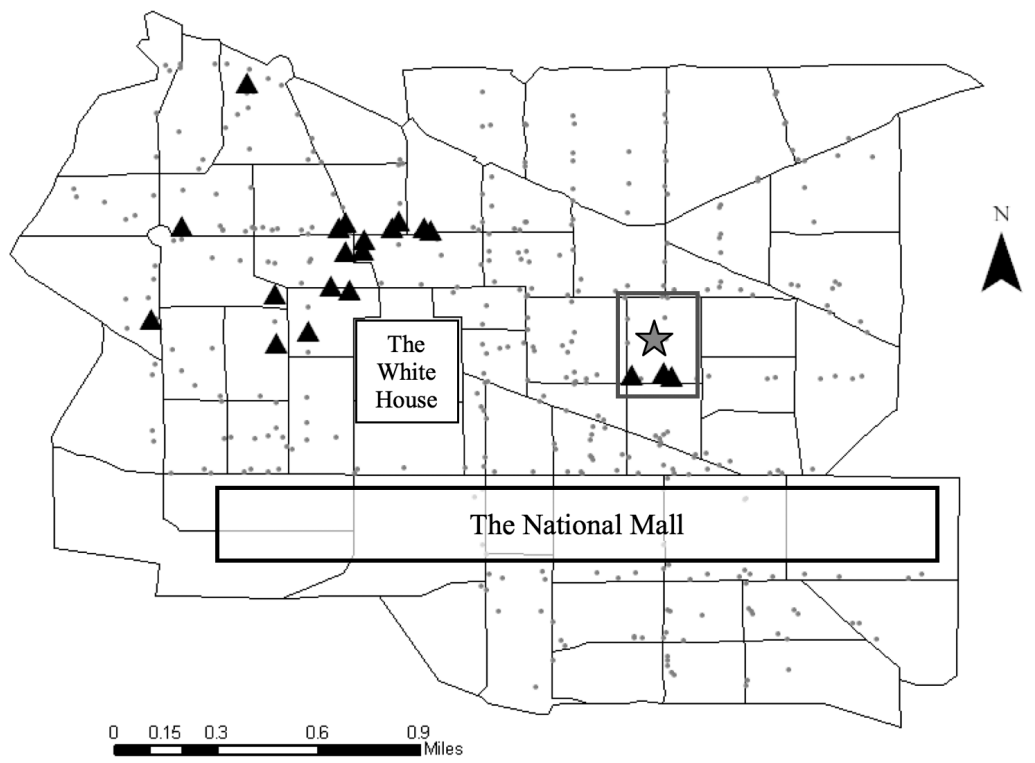

Figure 5a. Optimum 20 bus stops from trial 1

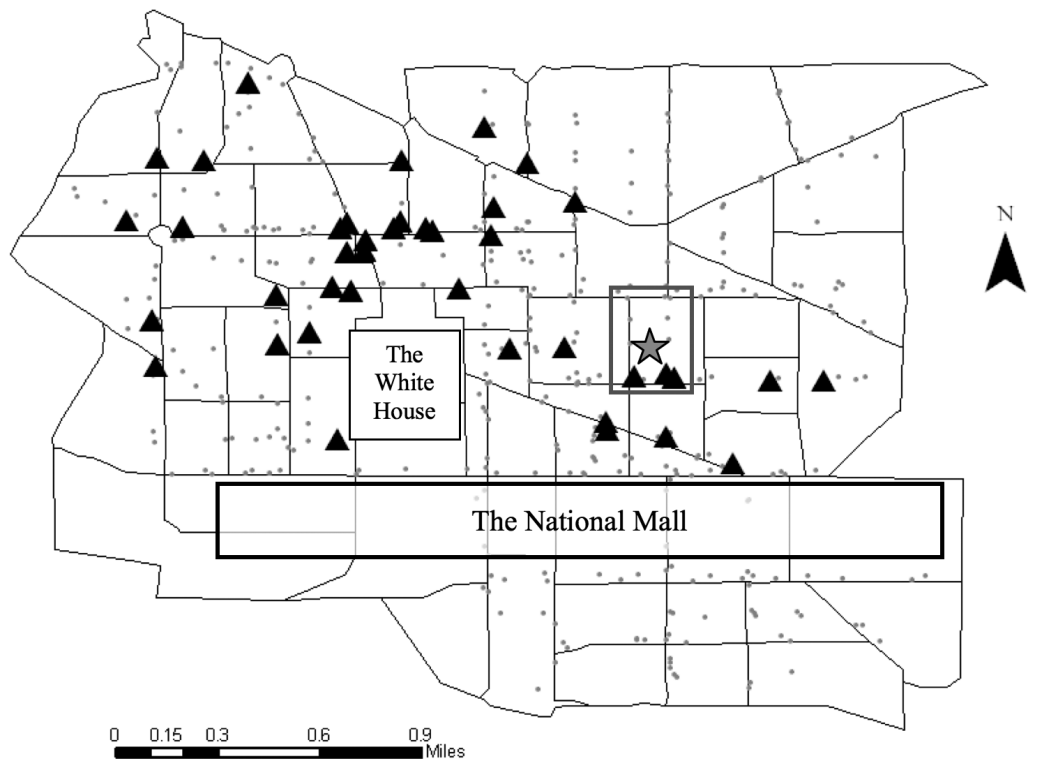

Figure 5b. Optimum 40 bus stops from trial 1 


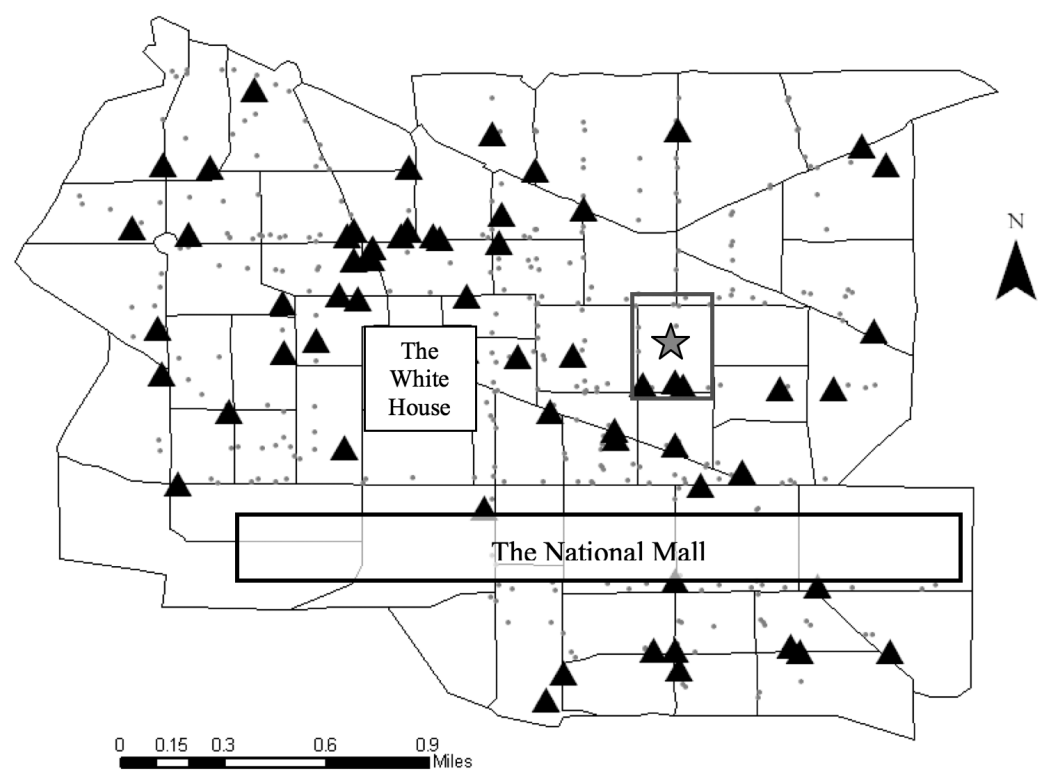

\section{Figure 5c. Optimum 60 bus stops from trial 1}

When the maximum number of bus stops was increased to 40 , the benefit of the bus stops also increased, to 68.3. This is a likely result in that the more bus stops selected, the more benefits the objective function will contain to sum. The bus stop locations seem to have an improved spatial spread throughout the downtown area. When examined closely, one can see a lack of evacuation bus stops in the lower third portion of the region, as well as the northeast corner. The lower portion of the case study area includes the National Mall and attracts many tourists daily. Therefore, it is vital that an evacuation bus stop is located in this area; extra constants were added to the formulation to account for this area (Figure 5b). This represents one of the biggest limitations of the study since very fine demographic data are required to properly represent the special needs population when calculating the benefit of bus stops. Collecting demographic data at the TAZ or census tract level is too broad to calculate the benefit of bus stop locations. Demographic data need to be collected at a finer level such as census block. Obtaining demographic data from the U.S. Census Bureau at the census block level produces a challenge because a majority of data is not readily available at this level.

After adding another 20 bus stops for a total maximum number of 60 bus stops (Figure $5 \mathrm{c}$ ), the maximum total benefit increased to 79.32. By allowing the model 
to choose 60 bus stop locations, the greatest benefit was achieved and the overall spatial distribution was greatly improved.

After reviewing the results of the mathematical formulation, the model was implemented for a second time to obtain results that would be more practical for actual planning purposes, even if a lesser number of maximum bus stops than 60 is required. The first set of bus stop location results yielded the stops with optimum benefit for special needs populations but did not take into account the travel time of the evacuee to reach the bus stop. If resources were available for 20 or 40 maximum evacuation bus stops, the optimization model will need to introduce additional constraints.

In an actual evacuation, bus stop locations must be available for service throughout the entire network and not in just one concentrated area. Despite that, this concentrated area is the one that resulted in the largest benefit, and it is understood that the bus stops should be more spatially distributed to serve all special needs populations throughout the entire downtown area to comply with practical evacuation planning. To prevent non-special needs people from taking the designated spaces of those with special needs, a priority policy should be implemented.

\section{Simulation Results}

The simulation results for this research are presented using specific measures of effectiveness: delay time (sec/mi), travel time (sec/mi), and stop time (sec/mi). All results presented are for buses only (the main objective of this research is focused on evacuation of public transit vehicles). A standard dwell time was calculated and applied to all evacuation bus stops. Using standards set by the Highway Capacity Manual (TRB 2010), a dwell time of $297.5 \mathrm{sec}$ was calculated. Results were recorded for five different replications for the five different maximum number of evacuation bus stop location scenarios.

By routing the evacuation buses to the nearest evacuation corridor, an attempt was made to keep delay time to a minimum. The largest delay time was experienced by the 40-bus-stop scenario ( $324 \mathrm{sec} / \mathrm{mi})$. The buses in the 20-bus-stop scenario could be experiencing a high delay $(309 \mathrm{sec} / \mathrm{mi})$ because of the congestion of all the buses serving the same small number of stops. The buses in this scenario had to be set to a very close headway (approximately $2 \mathrm{~min}$ ) to reach the required number of bus trips to evacuate the case study area. Due to the minimum headway interval and large dwell 
time, buses serving the same stop formed larger queues than in the other scenarios. The lowest delay time was experienced by the 60 -bus-stop scenario $(277 \mathrm{sec} / \mathrm{mi})$.

The travel time for each individual evacuation bus is dependent on the route of the evacuation bus. Several bus routes extended through the entire case study area, while others traveled just along the perimeter. The routing strategy implemented in this research tried to reduce travel time by exiting all evacuation buses to the nearest evacuation corridor after serving its assigned stop. Travel time is also dependent on which roadways the bus route serves and its level of service. The results found for travel time are consistent with the results obtained for delay time. This is due to delay time having a linear relationship with travel time experienced by the evacuation bus. If a bus experiences a larger delay time, the travel time will also increase. The average travel time for all the evacuation buses increased until reaching the 40-bus-stop scenario (399sec/mi). Again, the 40-bus-stop scenario had the highest result compared to other replications. On average, the travel time was lower for bus stop scenarios that contained more than 40 evacuation bus stops. The lowest average travel time resulted from the 60 -bus-stop scenario $(355 \mathrm{sec} / \mathrm{mi})$. The ranges for average travel time among all five scenarios were all within $50 \mathrm{sec} / \mathrm{mi}$. This might seem to be a minor difference, but when dealing with evacuation, time is of the essence.

The stop times found for each replication bus-stop scenario also followed the same patterned of the two previous sets of results. Replications for the 40-bus-stop scenario had the largest stop time when compared to the stop times for the other scenarios $(298 \mathrm{sec} / \mathrm{mi})$. The 60 -bus-stop scenario had stop times that were that were the lowest of all the scenarios $(252 \mathrm{sec} / \mathrm{mi})$.

The 40-bus-stop scenario yielded the highest delay, travel, and stop times and should not be implemented for evacuation. This could be due to the bus stop locations still requiring a large number of evacuation trips. It can be seen once the simulation is set for the 50-bus-stop scenario and the number of required trips per bus stop decrease from 50 to 40 , reducing the delay, travel, and stop time. Also, the bus routes required for this scenario might require longer evacuation travel distances.

After reviewing all the results for each measure of effectiveness, it can be seen that the 60-bus-stop scenario produced the most efficient evacuation time. Its delay, travel, and stop times were all the lowest when compared to the other simulated scenarios. This is due to the lower number of required buses per evacuation stop causing queues at evacuation stops for waiting evacuees. Furthermore, the stops were more evenly spatially distributed in this scenario, allowing for evacuation buses to slow evacuating traffic equally in the case study area and not just in con- 
centrated sections. More bus stop locations are located along the perimeter of the case study area, allowing for shorter bus evacuation routes.

Table 1 illustrates the delay time values obtained from the simulation runs for each scenario. Table 2 shows the stop time results, and Table 3 shows the travel time replication results for each of the five scenarios.

Table 1. Replication Results for Delay Time

Delay Time

\begin{tabular}{lcccccc}
\hline $\begin{array}{l}\text { Max \# } \\
\text { of Stops }\end{array}$ & 1 & 2 & 3 & 4 & 5 & Average \\
\hline 20 & 304.9500 & 316.8800 & 323.7080 & 293.2180 & 305.4180 & 308.8348 \\
30 & 303.0150 & 303.0150 & 334.4230 & 320.3780 & 316.2170 & 315.4096 \\
40 & 297.4840 & 308.7490 & 312.4250 & 364.8990 & 332.1250 & 323.1364 \\
50 & 289.6400 & 274.4120 & 294.4130 & 300.3200 & 276.4660 & 287.0502 \\
60 & 263.4640 & 282.1530 & 289.5380 & 280.9650 & 275.6950 & 278.3630 \\
\hline
\end{tabular}

Table 2. Replication Results for Stop Time

\begin{tabular}{lcccccc}
\multicolumn{7}{c}{ Stop Time } \\
\hline $\begin{array}{l}\text { Max \# } \\
\text { of Stops }\end{array}$ & 1 & 2 & 3 & 4 & 5 & Average \\
\hline 20 & 276.3660 & 289.5660 & 297.1250 & 270.2940 & 279.8580 & 282.6418 \\
30 & 278.1860 & 278.8617 & 309.0430 & 292.1400 & 288.2570 & 289.2975 \\
40 & 272.4660 & 280.9250 & 285.6800 & 339.1110 & 306.5860 & 296.9536 \\
50 & 262.8070 & 248.4450 & 267.1350 & 276.6740 & 250.6820 & 261.1486 \\
60 & 237.9410 & 256.7340 & 271.0770 & 254.5180 & 248.7960 & 253.8132 \\
\hline
\end{tabular}

Table 3. Replication Results for Travel Time

Travel Time

\begin{tabular}{lcccccc}
\hline $\begin{array}{l}\text { Max \# } \\
\text { of Stops }\end{array}$ & 1 & 2 & 3 & 4 & 5 & Average \\
\hline 20 & 381.2000 & 391.9100 & 399.2570 & 368.3680 & 381.4440 & 384.4358 \\
30 & 378.2540 & 378.2540 & 409.2590 & 395.4300 & 391.4850 & 390.5364 \\
40 & 372.9210 & 383.6340 & 388.0160 & 556.5450 & 407.2420 & 421.6716 \\
50 & 364.6600 & 349.3600 & 370.1970 & 375.9570 & 351.6610 & 362.3670 \\
60 & 339.3190 & 358.3510 & 373.1270 & 357.1650 & 350.7540 & 355.7432 \\
\hline
\end{tabular}

\section{Conclusions}

This study effectively addressed the optimal allocation of bus stops for the purpose of evacuating special needs populations. The proposed methodology was applied to a real-life case study to evaluate the effects of the location, number, and distribution of optimal evacuation bus stops. A microscopic traffic simulation model was 
developed to represent the downtown Washington, D.C. area in an evacuation scenario. Input data, such as geometric design, signal timing, traffic demand, and demographics, were used to construct the simulation model.

A linear programming mathematical model using binary variables was developed to select the most suitable location and number of bus stops catering to special needs populations in the network. A benefit function aggregated the attributes associated with each existing bus stop based on spatially-distributed demographic information. The formulation incorporated the preferences of the decision makers by associating weights with each specific special needs group. The flexibility of the formulation allows the decision maker to address specific concerns of the evacuation area. The use of a linear programming technique for the mathematical model presented in this research yielded satisfactory results. As mentioned earlier, the same formulation was optimized using a Genetic Algorithms solver for comparison purposes. However, this method required considerable computational time for convergence to the same optimal solution. It was then decided that a linear programming approach was the best for this research.

Simulating the optimum bus stop locations with the simulation model that was constructed for this research, evacuation performance results were obtained. As expected, the 20-bus-stop scenario produced very poor results and did not perform well under the evacuation scenario. The 60-bus-stop scenario created a very even spatial spread of evacuation bus stops throughout the case study area. It was assumed that this scenario would have large travel, delay, and stop times because of the diverse spread of resources and addition of extra bus routes. The results proved the opposite by showing satisfactory outcomes. The simulations for the 40-bus-stop scenario produced the highest results for all five replications. The 40-bus-stop scenario would not be ideal to implement for evacuation purposes for this case study. Each bus stop scenario that contained a greater number of bus stop locations performed superior. If the case study area has the resources to provide 60 evacuation bus stop locations, this scenario would be best for planning purposes. This scenario had the lowest delay, travel, and stop times with the best spatial spread of evacuation bus stops.

\section{Limitations}

The task of calibrating a large microscopic traffic network is one that requires the user to be familiar with the traffic conditions of the case study area and an ample amount of time to reconstruct the traffic conditions. Calibration is a very timeconsuming task and was a notable limitation in this research. The task of establish- 
ing origins and destinations does not take into account the travel path of vehicles, leaving the route choice model to determine vehicle paths. Traffic simulation includes considerable uncertainty, as it attempts to model human behavior which is very random, especially while simulating an evacuation scenario.

Several recommendations are made if this work is to be furthered.

- Some sort of penalty could be devised for bus stops that are located too close to each other to avoid clustering to add in the optimization formulation. Further grouping of TAZs could be developed to reduce the effects of clustering. A grid grouping method was introduced in this research but did not sufficiently separate the evacuation bus stop locations.

- The relationship/correlation between demographic groups could be explored further in order to avoid overemphasizing individuals that fall into multiple categories. Other implementations could include new target demographic groups. Census data for the specific demographic groups could be collected at the census block level instead of applying a percentage to the total population of the census block.

- The simulation portion of this research could be extended to explore more possibilities for evacuation planning. Different evacuation bus routes could be simulated, as could different headways and frequencies in which the buses depart or pick up evacuees. This research was limited to selecting optimum evacuation bus stop locations that currently act as bus stops in the everyday operation of the city. Future work could explore the possibility of using new bus stops that are not currently in use for everyday practice.

\section{References}

Alsnih, R., and P. R. Stopher. 2004. Review of procedures associated with devising emergency evacuation plans. Transportation Research Record, Journal of the Transportation Research Board 1865: 89-97.

Barcelo, J., and J. Casas. 2002. Dynamic network simulation with AIMSUN. International Symposium on Transport Simulations. Yokohama, August.

Burghout, W., H. K. Koutsopoulos, and I. Andréasson. 2005. Hybrid mesoscopicmicroscopic traffic simulation. Transportation Research Record: Journal of the Transportation Research Board 1934: 218-255.

Chen, X., and F. B. Zhan. 2008. Agent-based modeling and simulation of urban evacuation: Relative effectiveness of simultaneous and staged evacuation strategies. Journal of the Operational Research Society 59: 25-33. 
Chiu, Y-C., and P. B. Mirchandani. 2008. Online behavior-robust feedback information routing strategy for mass evacuation. IEEE Transactions on Intelligent Transportation Systems 9(2): 264-274.

Coolahan, J. E., K. L. Morse, and E. I. Kaisar. 2009. Modeling the relationship between hospital surge capacity and dynamic traffic condition. International Simulation Multi-Conference, Istanbul, Turkey, July.

Degnan, W. C., E. I. Kaisar, and J. W. Schokkin. 2009. A simulation model for bioterrorism preparedness in urban areas. Conference Proceedings, 3rd International Conference on Safety and Security, Rome, Italy.

Di Gangi, M., and P. Velona. 2009. Use of a multimodal mesoscopic approach in modeling pedestrian evacuation. Transportation Research Record: Journal of the Transportation Research Board 1956: 1-13.

He, S., L. Zhang, R. Song, Y. Wen, and D.Wu. 2009. Optimal transit routing problem for emergency evacuations. Transportation Research Record: Journal of the Transportation Research Board 0931.

Highway Capacity Manual. 2010. Transportation Research Board, Washington, D.C. Johnston, E., and B. Nee. 2006. A methodology for modeling evacuation in New Orleans. Department of City and Regional Planning, May, University of California, accessed 22 August 2009, <http://bnee.com/wpcontent/uploads/2006/10/ New_Orleans_Evacuation.pdf $>$.

Laben, C. 2002. Integration of remote sensing data and geographic information system technology for emergency managers and their applications at the Pacific Disaster Center. Optical Engineering 41(9).

L, T. 2006. Lessons from Katrina and Rita: What major disasters can teach transportation planners. Journal of Transportation Engineering (11)18, accessed 12 August 2009, <http://www.vtpi.org/katrina.pdf>.

Liu, Y., et al. 2008. A corridor-based emergency evacuation for Washington D.C.: System development and case study. Transportation Research Record: Journal of the Transportation Research Board 2041: 58-67.

Longley, R. 2009. Many U.S. cities see huge daily population swings: The effect of the "bedroom" suburbs. U.S. Government Info, October 2005, accessed 4 September 2009, <http://usgovinfo.about.com/od/censusandstatistics/a/daypop. htm.>. 
Mannan, M. S., and D. L. Kilpatrick. 2000. The pros and cons of shelter-in-place. Process Safety Progress 19(4): 210-218.

Mastrogiannidou, C., et al. 2009. Using transit to evacuate facilities in urban areas: A micro-simulation based integrated tool. Transportation Research Record: Journal of the Transportation Research Board 3439: 1-15.

Rabkin, M., R. Brodesky, F. Ford, M. Haines, J. Karp, K. Lovejoy, T. Regan, L. Sharpe, and M. Zirker. 2004. Transit security design considerations. U.S. Department of Transportation, Washington, D.C.

Renne, J. L., T. W. Sanchez, and T. Litman. 2008. national study on carless and special needs evacuation planning: A literature review. Federal Transit Administration, New Orleans .

Xiao, H., R. Ambadipudi, J. Hourdakis, and P. Michalopoulos. 2005. Methodology for selecting microscopic simulators: Comparative evaluation of AIMSUN and VISSIM. University of Minnesota, May.

\section{About the Authors}

Evangelos I. KAISAR (ekkaisar@fau.edu) is an Assistant Professor at Florida Atlantic University and hosts an active research program in transportation modeling. He formerly was a Project Manager in the Traffic Engineering Division of the Maryland Transportation Authority, where his technical activities included traffic and congestion pricing studies, simulation and modeling, and safety studies. He is currently the Principal Investigator for projects related to homeland security, intermodal safety and security, and pre-disaster mitigation. He holds B.S. degrees in Civil Engineering from the University of Maryland and NTIA of Athens, Greece, and M.S. and Ph.D. degrees in Civil Engineering from the University of Maryland at College Park.

LINDA HESS (equalgood@gmail.com) received M.S. and B.S. degrees in Civil Engineering from Florida Atlantic University. She currently works as a Traffic Engineer at Stanley Consultants, Inc. Her research interests include multi-modal transportation planning and transit and operations research.

Alicia Benazir Portal Palomo (aportalp@fau.edu) is a graduate student at Florida Atlantic University. She is currently working on the optimization of a hybrid model for transit systems by minimizing user and operator cost. Her research interests include transit operations, transportation planning, and pedestrian safety. 